\title{
Model Design of 3-Link Robotic Manipulator Using Maplesim Obasi C. C. ${ }^{* 1}$, Ikharo A. B. ${ }^{2}$, Okunowo B. A. ${ }^{3}$, Toye N. T. ${ }^{4}$, Oyesetan 0. R. ${ }^{5}$
}

\author{
1,2Department of Computer Engineering, Edo University Iyamho, Edo State, Nigeria \\ 3, 4, 5Department of Computer Engineering, Federal Polytechnic, Offa, Kwara State, Nigeria
}

\begin{abstract}
Article Info
Volume 7, Issue 5

Page Number: 01-06

Publication Issue :

September-October-2020
\end{abstract}

\section{Article History}

Accepted : 20 Aug 2020

Published : 04 Sep 2020

\section{ABSTRACT}

Robot design and development is a complex process and require critical analysis to be conducted before the actual implementation. Modern engineering application requires virtual models to be developed and simulated before the actual implementation is carried out. Maplesim has been identified as a tool that can be used for this purpose and has been used in this paper to demonstrate the development of 3-Link robotic manipulator. Design parameters were randomly selected and the symbolic tools in Maplesim were used to model the robot arm. Simulation of the model was done, while adjusting the values of the Proportional Integral Derivative (PID) controllers and the effect on the robot motion was visualized using graphs.

Keywords : Robot, Manipulators, Maplesim, PID, 3-Link, Kinematics, Dynamics

\section{INTRODUCTION}

Robots are special machine that assist humans in domestic, personal and industrial arenas, requiring specialized skills encompassing various engineering disciplines [1] to develop. Hence, robots finds useful place in assisting humans to carry out difficult, recurring tasks, or hazardous tasks with particular applications in remote operations [2], such as painting or nuclear plant operations. Considering the nature of work expected to be done by robots, one of the most important aspects of robot is design and development of the manipulator. [3] and [2] presented robot configurations based on their manipulator arrangements.
However, the design of robotic system is a complex process and require critical analysis to be conducted before the actual implementation. [1] noted that simulation is often faster and easier to carry out than prototype experiment in engineering design. During simulation, the real object is imitated [4] in a graphical model and gives parameters that represent the characteristics of the real object. [5] had used MATLAB to carry carryout analysis on Robot Manipulator Mechanism, in which the derived kinematic model was analysed for the position, velocity and acceleration of the links of the manipulator as well as the dynamics. [6] presented an analytical model of Kinematic analysis of robot manipulators with numerous mathematical analysis, [7] 
used MATLAB to evaluate Planar Robotic Arm Dynamics Based on An Improved Transfer Matrix Method for Multi-body Systems where the mathematical derivations were subjected to verifications. Kinematics model of an RA-02 (a 4 DOF) robotic arm was presented by [7] where MATLAB program based on Denavit-Hartenberg (DH) convention was used to analyse the direct kinematic problem. [8] demonstrated the use of specialize software known as MapleSim in the modelling and analysis of Robot Manipulators Position, Orientation and Coordinate Transformations.

An effort towards simplifying the design of 3 - links robotic manipulator was attempted in [9], where the mathematical modelling of both forward kinematics and inverse kinematics were presented. The work produces mathematical model for the various joints in the proposed manipulator for both forward and invers kinematics equations for the three joints involved as shown in Table I and Table II respectively.
Table I: Forward Kinematics equation for 3 joints [9]

\begin{tabular}{|l|c|l|}
\hline Joint & Angle & Value \\
\hline $\mathrm{J}_{1}$ & $\theta_{1}$ & $\left(\tan ^{-1}\left(y_{p} / x_{p}\right)\right)$ \\
& & $-\sin ^{-1} \frac{l_{2} \sin \left(180-\theta_{2}\right)}{\sqrt{x_{p}{ }^{2}+y_{p}{ }^{2}}}$ \\
\hline $\mathrm{J}_{2}$ & $\theta_{2}$ & $180^{0}$ \\
& & $+\left(\cos ^{-1} \frac{l_{1}{ }^{2}+l_{2}{ }^{2}-h^{2}}{2 l_{1} l_{2}}\right)$ \\
\hline
\end{tabular}

Table II: Inverse Kinematics equations for 3 joints [9]

\begin{tabular}{|c|c|c|}
\hline Joints & $x$-axis & $y$-axis \\
\hline $\mathrm{J}_{0}$ & 0 & 10 \\
\hline $\mathrm{J}_{1}$ & $l_{1} \cos \left(\theta_{1}\right)$ & $l_{1} \sin \left(\theta_{1}\right)$ \\
\hline $\mathrm{J}_{2}$ & $\begin{array}{l}l_{1} \cos \left(\theta_{1}\right) \\
+l_{2} \cos \left(\theta_{2}\right)\end{array}$ & $l_{1} \sin \left(\theta_{1}\right)+l_{2} \sin \left(\theta_{2}\right)$ \\
\hline
\end{tabular}

Further to this work, the model of the mathematics analysis of the proposed manipulator in [10] was developed in [11]. The work produced a set of equations for the forces at the respective joints of the proposed manipulator. Table III shows the set of torque equations that should act on the joints.

Table III: Dynamic Equations of the 3 joints [10]

\begin{tabular}{|l|c|c|}
\hline Joints & Torque & Value \\
\hline $\mathrm{J}_{0}$ & $\tau_{0}$ & $I_{0} \ddot{\theta}_{0}$ \\
\hline $\mathrm{J}_{0}$ & $\tau_{1}$ & $\begin{array}{c}\left(m_{1}+m_{2}\right) l_{1}{ }^{2} \ddot{\theta}_{1}+m_{2} l_{1} l_{2} \ddot{\theta}_{2} \cos \left(\theta_{1}-\theta_{2}\right)-m_{2} l_{1} l_{2} \dot{\theta}_{2}{ }^{2} \sin \left(\theta_{1}-\theta_{2}\right)+\left(m_{1}\right. \\
\left.+m_{2}\right) g l_{1} \cos \theta_{1}\end{array}$ \\
\hline $\mathrm{J}_{2}$ & $\tau_{2}$ & $m_{2} l_{2}{ }^{2} \ddot{\theta}_{2}+m_{2} l_{1} l_{2} \ddot{\theta}_{1} \cos \left(\theta_{1}-\theta_{2}\right)-m_{2} l_{1} l_{2} \dot{\theta}_{1}{ }^{2} \sin \left(\theta_{1}-\theta_{2}\right)+m_{2} g l_{2} \cos \theta_{2}$ \\
\hline
\end{tabular}

By inspection, the computational analysis done in [9] and [10] were only mathematical computation, which did not produce any physical or virtual model to verify the proposed model. Again, the implementation of such model will involve huge cost.
Furthermore, tools for virtual modelling like Matlab will require a lot of complex procedures.

This present work will be based on the models of [9] and [10], with an aim of using Maplesim software to illustrate and create the virtual model of rigid body of the proposed 3 -link robotic manipulator, improve the 
development process of robotic manipulators and also show the PID tuning effect of the manipulator during simulation.

\section{METHODOLOGY}

Maplesim is a symbolic modelling software that allows one to use graphical tools to develop design models instead of development from mathematical models. This software tool was used in this project to develop the model of the robot manipulator. Below are the compositions of the model, using the parameters in table IV (values were randomly selected for the purpose of this simulation).

Table IV : Design Parameter

\begin{tabular}{|l|l|l|l|}
\hline & Inertia, $\boldsymbol{I}$ & Mass, $\boldsymbol{m}$ & Length, $\boldsymbol{I}$ \\
\hline Link 0 & $10 \mathrm{~kg} \mathrm{~m}^{2}$ & $3 \mathrm{~kg}$ & $0.35 \mathrm{~m}$ \\
\hline Link 1 & $10 \mathrm{Kg} \mathrm{m}^{2}$ & $5 \mathrm{~kg}$ & $0.8 \mathrm{~m}$ \\
\hline Link 2 & $10 \mathrm{Kg} \mathrm{m}^{2}$ & $3.5 \mathrm{Kg}$ & $0.32 \mathrm{~m}$ \\
\hline
\end{tabular}

\section{A. 2D Model of the Robot}

Symbolic 2D model of the robot arm realized from the free body diagrams and equations above is shown in figure 1 below being the model of the design as was developed in Maplesim 6.4. The model has four main components, namely the Ramp, Servo, Base and Linkages.

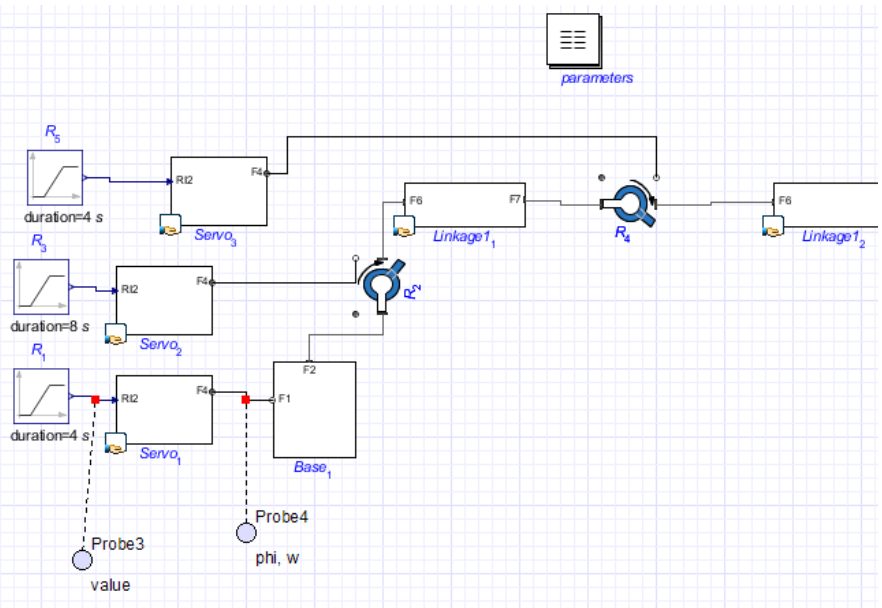

Figure 1 2D model of the Design
The Ramp component is used to initiate command at the joints of the robot. The PID block is a component of the servo block. The PID control block was used to control the speed of the DC motors at the joints and in this way control mechanical damping that could arise due to the speed of the motors. Figure 2 shows the PID block as was used in the model.

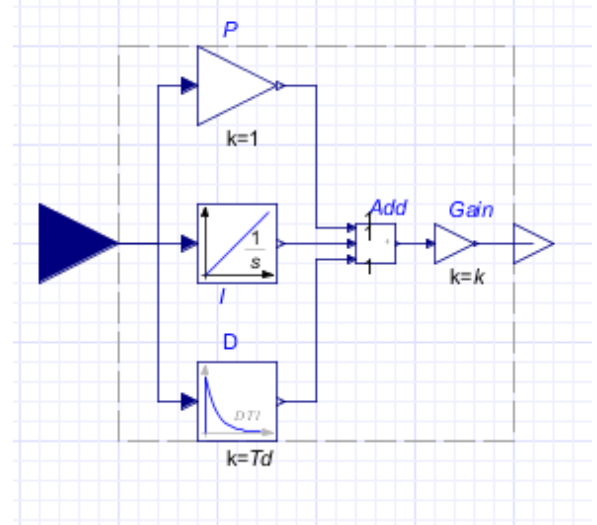

Figure 2 PID Block

Another component of the Servo block was the DC Motor block. This is shown in Figure 3 below.

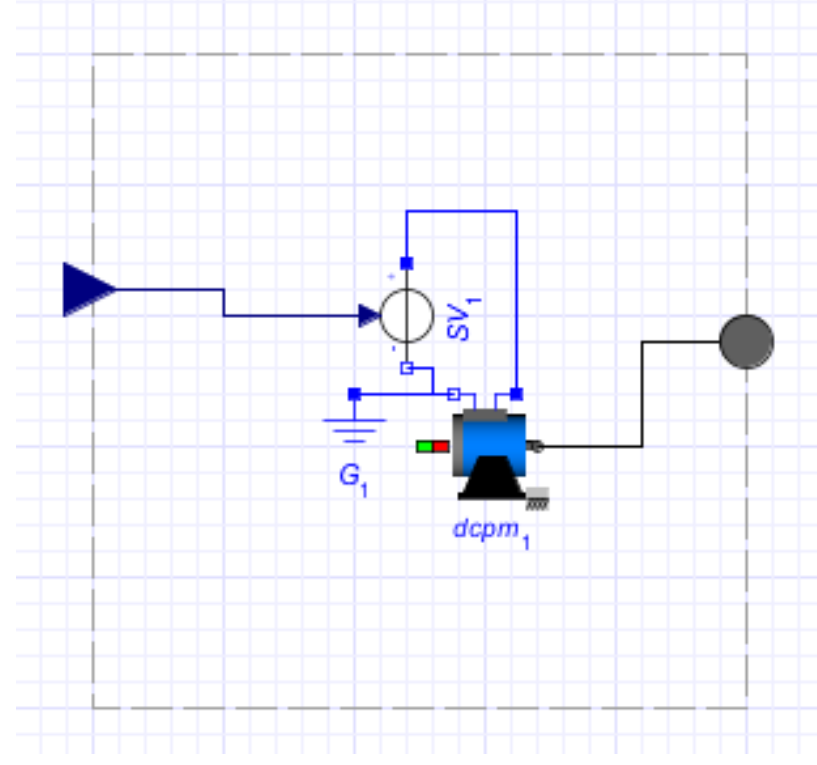

Figure 3 DC Motor Block

The DC Motor block provided the actuation signal that moved the joints of the robot.

The Base link was another major component of the robot model. This link provides a rotational motion in 
360 . The base block in the model is shown in Figure 4 below, with rigid body frame, mass and revolute joint.

The design parameter for the base were:
1. Inertia (I)
$=10 \mathrm{~kg} \mathrm{~m}^{2}$
2. $\quad$ Mass (m)
$=\quad 3 \mathrm{~kg}$
3. Length (10)
$=\quad 0.35 \mathrm{~m}$

The other linkages pose rigid body frames and masses. The parameters used were:
1. Inertia (I1 and I2) $\quad=10 \mathrm{~kg} \mathrm{~m}^{2}$
2. Mass ( $\mathrm{m} 1$ and $\mathrm{m} 2) \quad=5 \mathrm{~kg}$
3. Length (11 and 12) $\quad=0.62 \mathrm{~m}$ and $0.35 \mathrm{~m}$

The model sub block for the linkages is shown in Figure 5.

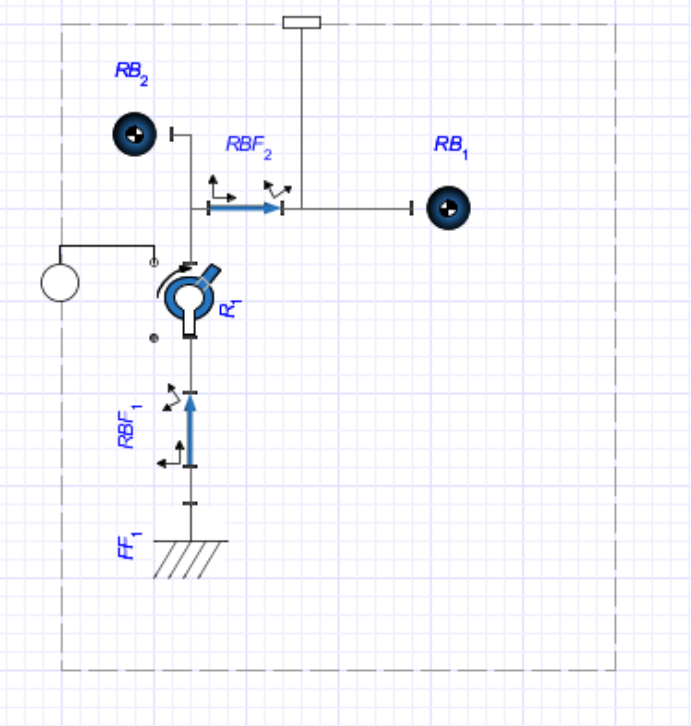

Figure 4 Base Link Block

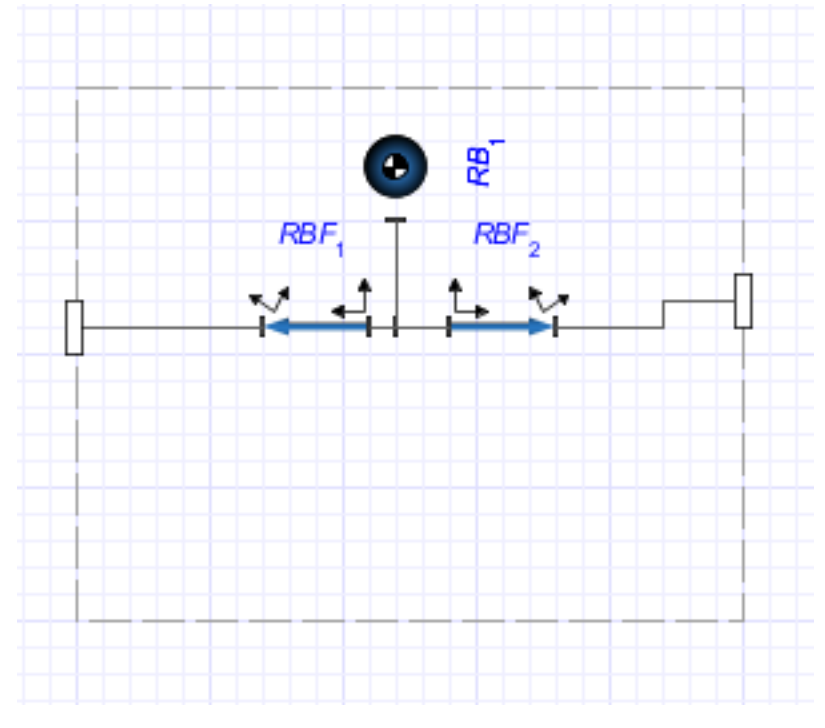

Figure 5 Robot Arm Linkages

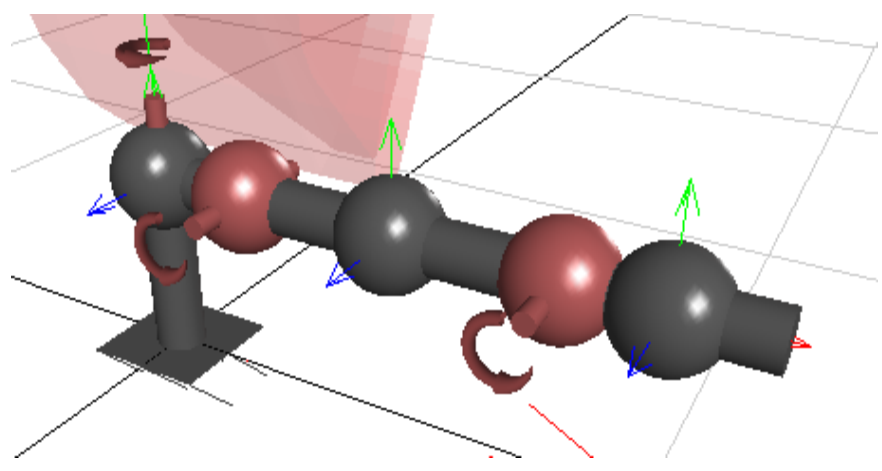

Figure 6 3D Model of the Robot Manipulator

\section{B. 3D Model of the Robot Design}

After the symbolic modelling in Maplesim, the model was compiled for simulation. One of the result of the simulation was the generation of $3 \mathrm{D}$ view of the model. This view is shown in Figure 6. The simulation results also generated mathematical equations for the kinematics and dynamics of the robot.

\section{RESULTS AND DISCUSSION}

The figures 7 to 9 were graphs generated to show the changes that occur as the robot changes location at the 3 joints. 
For the end effector, Theta2 changes is shown in Figure 7. This graph shows that the end effector follows the ramp but was affected by the vibration due to mechanical movement. It also shows that vibration began to be removed from the 4th second during the simulation. This was taken care of by the PID tuning values of $\mathrm{P}=3, \mathrm{I}=50$ and $\mathrm{D}=2$.

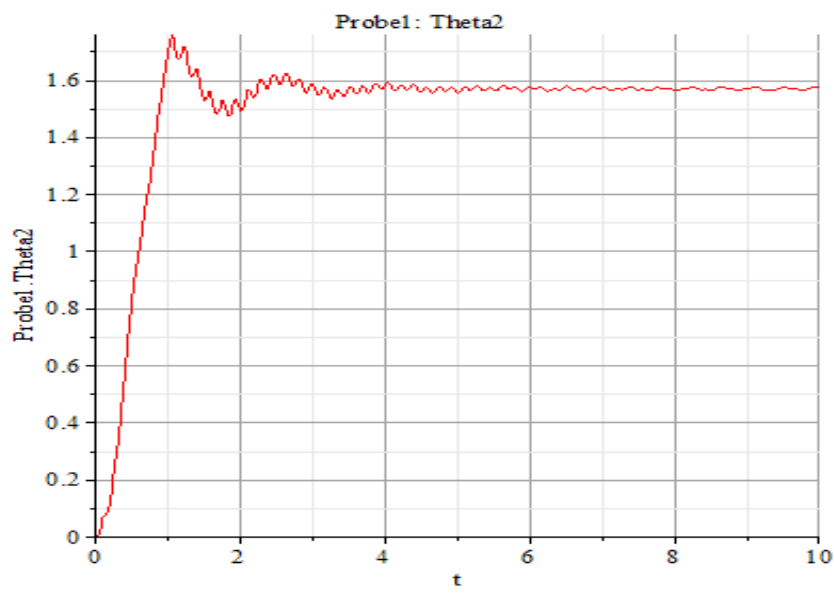

Figure 7 Angular displacement of the end effector

The displacement of the middle joint was controlled by the Theta1 as shown in Figure 8. From the graph, it is clear that vibration was much at this joint because the load here is much. However, the PID tuning was still able to reduce the vibration.

The PID values at this joints were $\mathrm{P}=5, \mathrm{I}=50$ and $\mathrm{D}=$ 10 .

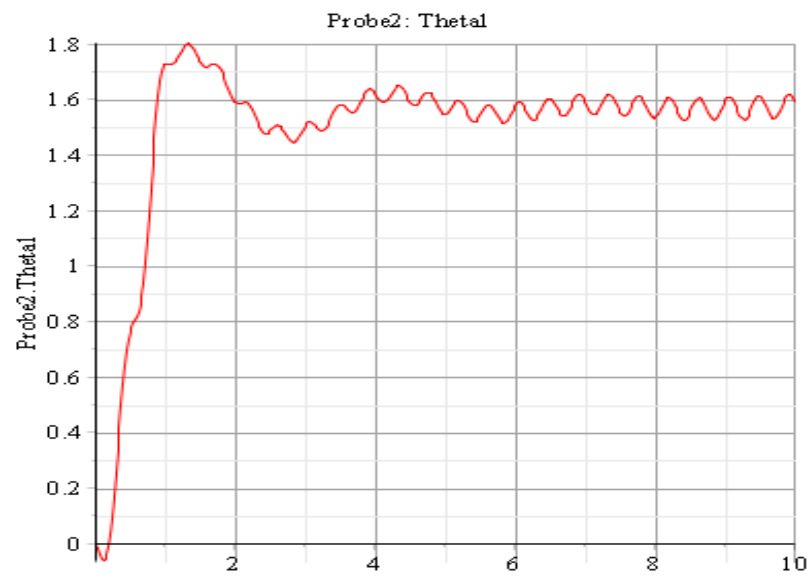

Figure 8 Angular displacement of Joint 1
At joint 0 , the angular displacement is as shown in Figure 9 below. The graph shows that vibration was also felt at this joint during the rising time of the ramp, but was removed by the PID tuning. From 4 seconds, the curve appears smoother than the other joints.

The PID values at this joint were $\mathrm{P}=1, \mathrm{I}=15$ and $\mathrm{D}=$ 5.

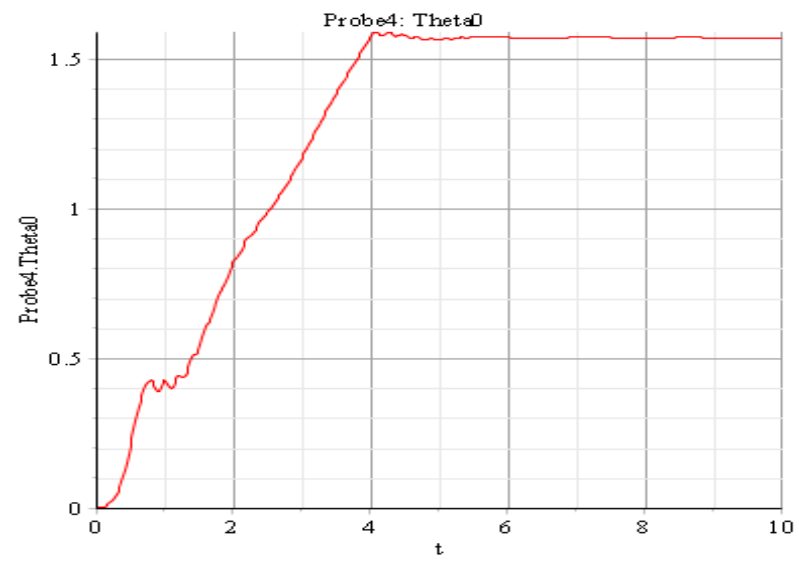

Figure 9 Angular displacement of Joint 0

\section{CONCLUSION}

Model design and simulation is a modern practice in engineering design and development. Maplesim was used to demonstrate symbolic development and simulation of robot arm model from the 2 dimensional view to 3 dimensional view. Given the appropriate parameters, it is certain that design issues can be monitored and controlled at the early stage of development to minimise material wastage while ensuring that products quality are optimised. The result also show that PID tuning will reduce the effect of bouncing on the manipulator arm.

\section{REFERENCES}

[1]. K. Raza, T. A. Khan, and N. Abbas, "Kinematic analysis and geometrical improvement ofRaza, K., Khan, T. A., \& Abbas, N. (2018). Kinematic 
analysis and geometrical improvement of an industrial robotic arm. Journal of King Saud University - Engineering Sciences. https://doi.org/10.1016/j.jksu," J. King Saud Univ. - Eng. Sci., 2018.

[2]. R. M. Murray, Z. Li, and S. Shankar Sastry, A mathematical introduction to robotic manipulation. 2017.

[3]. F. L. Lewis, D. M. Dawson, and C. T. Abdallah, Robot Manipulator Control. Theory and Practice. 2004.

[4]. S. S. Rai, T. A. Gaikwad, and R. V. Kulkarni, "A Research Paper on Simulation Model for Teaching and Learning Process in Higher Education," Int. J. Adv. Comput. Res., vol. 4, no. 2, pp. 2277-7970, 2014.

[5]. P. Badoniya, "Two Link Planar Robot Manipulator Mechanism Analysis with MATLAB,” Int. J. Res. Appl. Sci. Eng. Technol., 2018, doi: 10.22214/ijraset.2018.7132.

[6]. S. Kucuk and Z. Bingul, "Robot Kinematics: Forward and Inverse Kinematics," in Industrial Robotics: Theory, Modelling and Control, 2006.

[7]. W. Chen, H. Li, and X. Z. Zhang, "Modelling and analysis of planar robotic arm dynamics based on an improved transfer matrix method for multibody systems," 2015, doi: 10.6567/IFToMM.14TH.WC.OS13.046.

[8]. MAplesoft, "Robot Manipulators Position, Orientation and Coordinate Transformations," Online]. Available: https://www.maplesoft.com/engineeringfunda mentals/topic. aspx?tid=13.

[9]. C. C. Obasi, A. B. Ikharao, V. A. Balogun, A. Odaba, and L. I. Ogbewey, "Computational Analysis of Kinematics of 3 - Links Articulated Robotic Manipulator," Int. J. Eng. Adv. Technol., vol. 9, no. 2, pp. 3640-3643, 2019.

[10]. C. C. Obasi, A. B. Ikharo, A. Odaba, L. I. Ogbewey, and B. A. Oluyomi, "Dynamics of 3 Links Articulated Robotic Manipulator: A
Computational Model," Int. J. Eng. Adv. Technol., vol. 9, no. 3, pp. 1911-1915, 2020.

\section{Cite this article as :}

Obasi C. C., Ikharo A. B., Okunowo B. A., Toye N. T., Oyesetan O. R., "Model Design of 3-Link Robotic Manipulator Using Maplesim", International Journal of Scientific Research in Science and Technology (IJSRST), Online ISSN : 2395-602X, Print ISSN : 23956011, Volume 7 Issue 5, pp. 01-06, September-October 2020. Available at doi : https://doi.org/10.32628/IJSRST207449 Journal URL : http://ijsrst.com/IJSRST207449 